University of Nebraska - Lincoln DigitalCommons@University of Nebraska - Lincoln

2009

\title{
Field System for Isoflurane Anesthesia of Multiple Species of Mesopredators
}

Larkin A. Powell

University of Nebraska-Lincoln, lpowell3@unl.edu

Follow this and additional works at: http://digitalcommons.unl.edu/natrespapers

Powell, Larkin A., "Field System for Isoflurane Anesthesia of Multiple Species of Mesopredators" (2009). Papers in Natural Resources. 408.

http://digitalcommons.unl.edu/natrespapers/408

This Article is brought to you for free and open access by the Natural Resources, School of at DigitalCommons@University of Nebraska - Lincoln. It has been accepted for inclusion in Papers in Natural Resources by an authorized administrator of DigitalCommons@University of Nebraska - Lincoln. 


\title{
A Field System for Isoflurane Anesthesia of Multiple Species of Mesopredators
}

\begin{abstract}
Inhaled isoflurane is one of many chemical immobilizing agents available for field anesthesia of wildlife. We examined the use of inhaled isoflurane for field immobilization of mesopredators. Five species of mammals were anesthetized in a wetland complex in south-central Nebraska with isoflurane; we developed an induction chamber to use with a portable anesthesia machine to provide anesthesia at the capture location. Sixteen raccoons (Procyon lotor), 20 striped skunks (Mephitis mephitis), 4 Virginia opossums (Didelphis virginiana), 2 American badgers (Taxidea taxus) and 1 mink (Mustela vison) were captured and immobilized; we radio-marked 11 raccoons and 9 skunks. Induction was smooth and uneventful for all species immobilized. Mean induction times for raccoons and skunks were $10.7 \mathrm{~min}(\mathrm{SD}=1.1)$ and $11.0 \mathrm{~min}(\mathrm{SD}=2.4)$ respectively. Mean handling times (postinduction) were $7.1 \mathrm{~min}(\mathrm{SD}=3.9)$ for raccoons and $7.3 \mathrm{~min}(\mathrm{SD}=4.8)$ for skunks. All animals, with the exception of opossums, were fully recovered within $15 \mathrm{~min}$ (raccoon mean recovery: $11.1 \mathrm{~min}, \mathrm{SD}=3.5$; skunk mean recovery: $10.9 \mathrm{~min}, \mathrm{SD}=3.7$ ). Recovery times for radio-collared animals and uncollared animals did not differ, and individuals with longer handling times did not require longer recovery times. Although isoflurane requires more equipment than injectable anesthesia methods, its short recovery time and wide safety margins deem it practical for use in a variety of field applications.
\end{abstract}

\section{INTRODUCTION}

Immobilizing agents for field anesthesia of wildlife are available in a variety of combinations, each varying in effectiveness relative to species, body weight, specific combinations and dosages (Seal and Kreeger, 1987; Mathews et al., 2002). Acceptable anesthesics yield an animal completely unconscious, unable to perceive pain and provide for a complete and rapid recovery (Osofsky and Hirsch, 2000).

Common injectable anesthetic agents used to immobilize mesopredators in the field include ketamine (often combined with xylazine, acepromazine or medetomidine), telazol, fentanyl-droperidol and phencyclidine and pentobarbital sodium (Kreeger, 2007; reviewed by Kocer, 2004). Dosages of injectable immobilizing agents are body weight dependent and few serious side effects have been reported in the preceding studies. Induction times reported were rapid (usually $<5 \mathrm{~min}$ ) for these drugs but recovery times were prolonged in many cases $(0.3-4.0 \mathrm{~h})$.

Inhalation anesthetics have been used in very few field settings (Feldman and Self, 1971; Taulman and Williamson, 1993; Lariviere and Messier, 1996a, 1996b), limited mainly to young animals or species small enough to be manually restrained or enclosed in a bag or box (Seal and Kreeger, 1987). However, inhalation anesthetics offer good control over the depth and duration of anesthesia and they follow the dose-response concept (i.e., effect increases as the dose increases; Seal and Kreeger, 1987; Kreeger $e t$ al., 1998).

Isoflurane inhaled anesthesia is commonly used in human and veterinary medicine, and has recently become suitable for field use with the advent of a portable vaporizer. Isoflurane is one of the least toxic inhalation anesthetics available today (Belant, 1995), providing smooth induction and recovery for anesthetized animals (Seal and Kreeger, 1987). Isoflurane does not require mixing drugs for induction or reversal agents. Because needles are not used, potential human contact with the drug is greatly reduced. Not all injectable agents or combinations are completely reversible and many are associated with prolonged recovery times (Mathews et al., 2002). For example, Kreeger et al. (1998) reported that black-footed ferrets appeared more physiologically normal under isoflurane than under injected medetomidine and ketamine.

Isoflurane has been successfully used in field studies to anesthetize muskrats (Ondatra zibethicus; Belant, 1995), beaver (Castor canadensis; Breck and Gaynor, 2003), Siberian polecats (Mustela eversmanni; Gaynor et al., 1997), Steller's sea lions (Eumetopias jubatus, adults and pups; Heath et al., 1996; Heath et $a l ., 1997)$ and black-footed ferrets (M. nigripes, Kreeger et al., 1998). Despite the benefits of using isoflurane, it is not commonly used to anesthetize mesopredators (Lewis, 2004) because it is difficult to use an induction chamber in the field. 
In the present study, isoflurane was used on multiple species in short-duration procedures in the field because of its simplicity, rapid induction and recovery, and minimal side effects (Seal and Kreeger, 1987). Previous studies have not examined the effects of isoflurane anesthesia on recovery times. Our study is the first to document the concurrent use of isoflurane on five mesopredator species. The objectives of our study were to (1) develop a useful chamber for the use of isoflurane gas as a field anesthesia for a suite of mesopredators and (2) determine the effect of anesthetized handling time on animal recovery time.

\section{MetHods}

STUDY AREA AND TARGET SPECIES

Our research was conducted during 2002 and 2003 as part of a mesopredator study in the Rainwater Basin wetlands of south-central Nebraska (Kocer, 2004). We captured animals in wire box traps for a 4-5 d period twice between May and August each year. Raccoons (Procyon lotor) and striped skunks (Mephitis mephitis) were the primary target species of our study based on abundance, ease of capture and ability to carry a radio transmitter. We radio-marked a subsample of raccoons and skunks using 30 -g radio collars (model MI-2, Holohil Systems Ltd. Corp, Ontario, Canada). We also captured Virginia opossums (Didelphis virginiana) and American badgers (Taxidea taxus), which were also radio-collared when possible. We captured one mink (Mustela vison).

\section{FIELD ANESTHESIA METHODS}

We anesthetized captured animals with isoflurane (MWI Veterinary Supply Co., Nampa, ID) using a portable anesthesia machine, designed by Dr. R. B. Heath, DVM (Seven Seven Anesthesia, Fort Collins, CO; Fig. 1). The machine was fully portable (weight: $11.5 \mathrm{~kg}$ ), easily constructed and collapsed in minutes. The unit consisted of a vaporizer connected to a Baines non-rebreathing circuit with side port bag and valve. Non-rebreathing systems are light-weight, offer reduced breathing resistance, and are useful for smaller animals or animals with unknown respiratory problems that may not be immediately apparent in the field (Lerche $e t$ al., 2000). Use of a precision-calibrated vaporizer allowed us to utilize the control advantages offered by inhalation anesthetics (Seal and Kreeger, 1987). The entire machine sat on a telescoping tripod that adapted to uneven terrain. The vaporizer was connected to a portable medical oxygen cylinder (size E) using standard circuitry.

Previous studies used clear plastic (Gaynor et al., 1997), Plexiglas ${ }^{\circledR}$ (Kreeger et al., 1998) or wooden (Balser and Kinsey, 1962) boxes, as well as transparent polyethylene bags (Mathews et al., 2002) as induction chambers for inhalation anesthesia. However, these chambers were inadequate for our multispecies study in a temperate grassland/wetland landscape that afforded little shade. The species in this study required a chamber that could accommodate a wide range of body sizes and provide shade from the sun during induction. We found that our traps punctured heavy plastic bags, making them inefficient. Thus, we constructed an improved induction chamber by modifying an opaque, plastic outdoor garbage can (dimensions: diameter, top $=48 \mathrm{~cm}$ and base $=38 \mathrm{~cm}$; height $=78 \mathrm{~cm}$ ). We chose to use a tall cylindrical chamber to make it difficult for the animal to escape as it was transferred from the trap to the chamber. The opaque color of the chamber kept the animal shaded from the sun during induction, and the darkened chamber helped to quiet the animal, promoting a smooth induction (Mathews et al., 2002).

We constructed a plunger to make the chamber's volume adjustable, seal the animal into the chamber and minimize the volume to be filled with the isoflurane/oxygen mixture needed to anesthetize the animal. The plunger (dimensions: top diameter: $46 \mathrm{~cm}$, base diameter: $35 \mathrm{~cm}$, height: $14 \mathrm{~cm}$ ) was constructed from a plastic tub (\#H11501, Wal-Mart Stores, Inc., Bentonville, AR) cut to fit the opening of the garbage can. A $64-\mathrm{cm}^{2}$ observation window was cut into the bottom of the tub, fitted with Plexiglas ${ }^{\circledR}$ and reinforced with plywood so that we could observe the animal while in the chamber (Fig. 2). The top, outer edge of the plunger was fitted with a bicycle inner tube to create an airtight seal, which prevented isoflurane from escaping the chamber. We attached handles to the plunger base, and we could depress the plunger to a level just above the animal. To connect the chamber to the anesthesia machine, we fitted a short rubber pipe into a hole cut through the floor of the plunger in which a hose was fitted to administer the anesthesia (Fig. 2). 


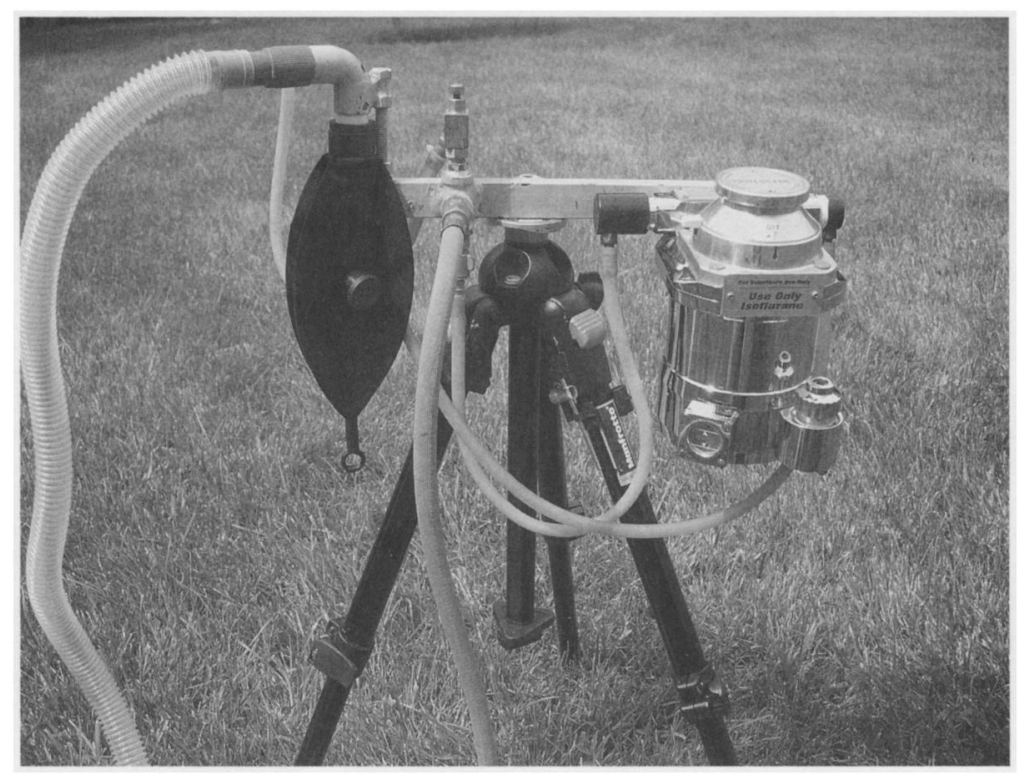

FIG. 1.-Field-suitable isoflurane gas anesthesia vaporizer used to immobilize mesopredators in the field (Rainwater Basin region, south-central Nebraska). Designed by Dr. R. B. Heath, DVM (Seven Seven Anesthesia, Fort Collins, CO)

We transferred captured animals from a live trap into the induction chamber; we used a heavy cloth bag to move the animal from the trap to the chamber. Transfers were easily accomplished and occurred without incident. Animals (e.g., mink) captured in smaller traps could be placed directly in the indication chamber with the trap. Once the animal was inside the chamber, we depressed the plunger to a depth of approximately $50 \mathrm{~cm}$ from the top of the chamber, just above the animal. Because isoflurane anesthesia dose is not body-weight dependent, we did not need to weigh captured animals before induction.

We administered a concentration of $5 \%$ isoflurane in $3 \mathrm{~L}$ of oxygen per minute. After approximately $10 \mathrm{~min}$, we checked the animal to evaluate the degree of immobilization, and more time was allotted when necessary. During induction, we used the plunger window to watch for laryngospasm, coughing, breath holding and agitation; we monitored the chamber for increased secretions when we removed the animal. Complete immobilization was determined by unresponsiveness to stimuli, such as movement of the induction chamber. Induction time was defined as the period during which the inhalant gas was turned on until the animal was removed from the chamber. Upon complete immobilization, we removed the animal from the chamber, decreased the concentration of isoflurane to $3 \%$ in $3 \mathrm{~L}$ of oxygen per minute, and placed a small, standard nose cone fitted with a rubber ring over the animal's muzzle to maintain immobilization during handling. The animal was placed on a foam mat during handling to reduce heat loss (Mathews et al., 2002).

We defined handling time as the amount of time the animal was out of the chamber, with a nose cone securely over its nose and mouth. While unconscious, the animal was sexed, weighed and ear tagged, and we marked a subsample with radio-collars. We continued to use anesthesia until these procedures were complete, then placed the animal in a transport kennel to recover after the anesthesia was turned off, and we allowed the animal to recover. Complete recovery was determined by alertness, ability to stand upright and ability to move in the kennel without stumbling. Recovery time was defined as the time from removal of the nose cone until release. Each animal was released at its capture site after it was fully recovered, and all equipment was thoroughly disinfected with bleach wipes between individuals. 


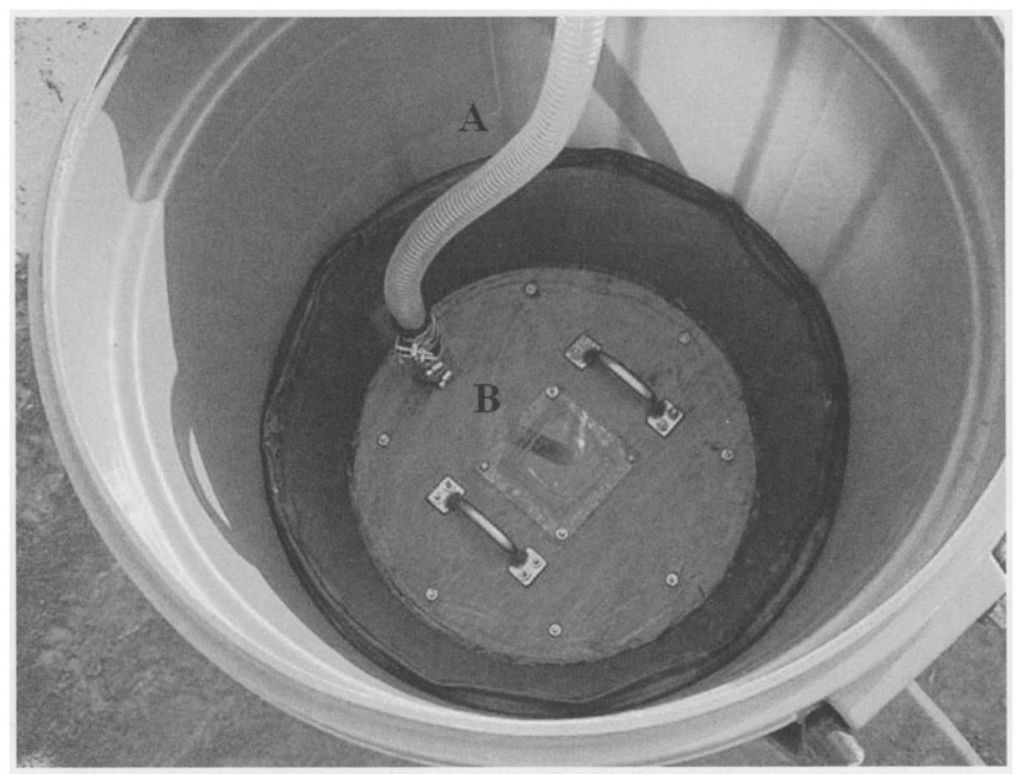

FIG. 2.-Isoflurane gas anesthesia chamber shown with plunger depressed. Labels are: (A) the hose that administered the anesthesia (see Fig. 1, left) and (B) the Plexiglas window used to observe the animal during induction

We located radio-marked animals the night after marking to evaluate movement and survival following anesthesia induction. The University of Nebraska-Lincoln's Institutional Animal Care and Use Committee (IACUC) approved our research methods prior to our field work (University of NebraskaLincoln IACUC Permit \#01-12-075).

\section{STATISTICAL ANALYSIS}

We focused our statistical analyses on raccoons $(n=16)$ and skunks $(n=20)$, which had the largest sample size, although we used isoflurane anesthesia on all captured mesopredators. During anesthesia, we recorded the time at four points: (1) when the anesthesia gas was initially turned on, (2) when immobilization was achieved and the level of isoflurane/oxygen gas was reduced, (3) when the nose cone was removed and (4) when the animal was released. We used a two-sample t-test to compare induction, handling and recovery times between raccoons and skunks; induction times for badgers and opossums had smaller sample sizes, and we used mean induction times and associated SD for comparisons. Our working hypothesis was that isoflurane would work equally well for our target species; we tested that hypothesis by looking for statistically similar induction and recovery times. Speciesspecific excitability levels could also cause differences in induction.

Some animals in our sample were radio-marked with a collar. Because of the time needed to attach the collar, radio-marked individuals spent more time under anesthesia (handling time) than individuals that did not receive radio collars. We used a linear regression analysis to determine if longer handling times resulted in longer recovery times.

\section{RESULTS}

During 2002 and 2003, we captured and immobilized 16 raccoons (2002: 10; 2003: 6), 20 skunks (2002: 10; 2003: 10), 4 opossums (2002: 2; 2003: 2) and 2 badgers (2003). In 2002, we also immobilized one mink. We radio-marked 11 of 16 raccoons and 9 of 20 skunks captured. Each animal was only immobilized once during our study as we did not recapture any animals. Radio telemetry indicated that all radio-marked animals survived the first week following capture and anesthesia. 
TABLE 1.-Mean times, in min (SD), required to for immobilization, handling and recovery of five various species using an inhaled isoflurane anesthesia

\begin{tabular}{|c|c|c|c|c|c|c|}
\hline \multirow[b]{2}{*}{ Species } & \multirow[b]{2}{*}{$\mathrm{n}$} & \multirow[b]{2}{*}{ Induction } & \multicolumn{2}{|c|}{ Handling } & \multicolumn{2}{|c|}{ Recovery } \\
\hline & & & Collared $^{\mathrm{a}}$ & Uncollared & Collared $^{\mathrm{a}}$ & Uncollared \\
\hline Raccoon & 16 & $10.7(1.1)$ & $8.8(3.4)$ & $3.2(1.1)$ & $10.7(4.0)$ & $11.8(2.5)$ \\
\hline Striped Skunk & 20 & $11.0(2.4)$ & $11.1(4.2)$ & $4.18(2.4)$ & $10.2(5.1)$ & $11.5(2.1)$ \\
\hline American Badger & 2 & $17.5(2.1)$ & $20^{\mathrm{b}}$ & $10^{\mathrm{b}}$ & $14^{\mathrm{b}}$ & $10^{\mathrm{b}}$ \\
\hline Virginia Opossum & 4 & $13.0(8.1)$ & $6^{\mathrm{b}}$ & $3.7(4.7)$ & $14^{\mathrm{b}}$ & $19.7(11.2)$ \\
\hline Mink & 1 & $10^{\mathrm{b}}$ & & $5^{b}$ & & $10^{\mathrm{b}}$ \\
\hline
\end{tabular}

${ }^{\text {a }}$ Radio-collared sample sizes: 11 of 16 raccoons, 9 of 20 skunks were radio-collared; 3 of 4 opossum and 1 badger

${ }^{\mathrm{b}}$ No SD; $\mathrm{n}=1$

Induction was smooth and uneventful for all species immobilized. Mean induction times did not differ between raccoons and skunks (Table $1 ; t_{27}=0.43, P=0.33$ ). Induction time for the two badgers was higher than for raccoons and skunks, possibly due to their excited states after capture. The four opossums had variable induction times (Table 1). We did not observe laryngospasm, coughing, breath holding, increase in secretions or agitation for any species during induction.

Mean handling times did not differ between raccoons and skunks $\left(t_{34}=0.16, P=0.44\right)$. There was a significant difference in handling times for radio-collared versus uncollared individuals (Table $1 ; t_{30}=$ 5.91, $P<0.001)$. Mean handling time for collared individuals was $9.9 \mathrm{~min}(\mathrm{SD}=3.9)$ and uncollared individuals was $3.9 \mathrm{~min}(\mathrm{SD}=2.1)$.

All animals, with the exception of opossums, were fully recovered within $15 \mathrm{~min}$ (Table 1). Recovery time for collared individuals (mean: $10.5 \mathrm{~min}, \mathrm{SD}=4.39$ ) did not differ from uncollared individuals (mean: $11.6 \mathrm{~min}, \mathrm{SD}=2.13 ; t_{29}=0.95, P=0.17$ ); this pattern held for raccoons and skunks (Table 1 ). Longer handling times did not require longer recovery times (slope $=-0.12, R^{2}=0.02, P=0.41$ ).

\section{Discussion}

We did not observe any adverse effects or deaths during anesthesia or recovery as a result of isoflurane immobilization. We normally administered isoflurane for $10 \mathrm{~min}$ before disturbance to ensure immobilization before handling, and the 10-minute induction time worked well for our study's objectives. Belant (1995) reported an extremely prolonged induction time using isoflurane in muskrats (18-24 min for adults), which may be due to the fact that an isoflurane soaked cotton ball was used rather than a vaporizer and oxygen. Higher levels of oxygen help to promote rapid induction (Dr. C. Morgan D.V.M., pers. comm.). Excitement levels also contribute to a prolonged or unsuccessful immobilization; a calmer animal will undergo a safer and smoother induction (Seal and Kreeger, 1987).

We observed no differences in recovery among the target species of our study. In three instances, the animal became very active after only 2-3 min following the conclusion of isoflurane anesthesia. Although induction is more rapid using injectable anesthetics, recovery appears to be considerably shorter using inhaled isoflurane. Opossum recovery time $(18.3 \mathrm{~min}, \mathrm{SD}=9.6)$ may have been artificially inflated, as opossums, by their nature, feign death as a defense mechanism. In one instance, we observed an individual for over $30 \mathrm{~min}$ after anesthesia was removed; this long "recovery" inflated the average recovery time for opossums.

Biologists must consider several characteristics of anesthesia systems as they plan field experiments. Portable anesthesia systems are relatively expensive in comparison to injectable systems. In 1998, Kreeger et al. (1998) reported that their portable gas anesthesia system cost approximately $\$ 7,000$. However, the system that we used cost significantly less $(\$ 1,400)$, suggesting that this method is becoming more affordable. Isoflurane is inexpensive $(\$ 60$ per $250 \mathrm{~mL})$ and easy to handle. It comes in a liquid form and is stored at room temperature. Although isoflurane anesthesia mechanisms are bulkier than injectible anesthesia equipment, we operated efficiently from a pick-up truck at roadside wetlands. Heath et al. (1996) used backpacks to transport this anesthetic equipment when study animals 
were trapped at a remote location; we considered the use of all-terrain vehicles to transport equipment in our study.

Our modified anesthesia chamber allowed us to anesthetize mesopredators with a variety of body sizes. The use of an isoflurane system as sole anesthesia is best suited for small to medium sized animals. Because of complications of delivery during induction, larger mammals will likely need to be immobilized using an injectable anesthetic; isoflurane can be used to prolong anesthesia as Heath $\mathrm{et} \mathrm{al}$. (1996) reported in Steller's sea lions.

In conclusion, isoflurane inhaled anesthesia produced smooth and uneventful induction and recovery in the mesopredators considered in this study. The additional time under anesthesia required to radio-mark animals did not affect recovery times. Our study suggests that isoflurane can be a suitable anesthesia for mesopredators in many field situations. Isoflurane requires more equipment than injectables, but its ease of use and wide safety margins make it practical for use in a variety of field applications.

Acknowledgments. -We would like to acknowledge J. Curinga, K. Neiderklein, M. Post van der Burg, Z. Cunningham and M. Metz for their help in the field. Dr. K. Amass D.V.M, Dr. C. Morgan D.V.M. and Dr. B. Heath D.V.M. were invaluable in the development and implementation of this form of field anesthesia. R. Bischof (Nebraska Game and Parks Commission) and J. Curinga designed the chamber used in this study. The Nebraska Game and Parks Commission provided funding, research vehicles and technical support and the University Research Council (UNL) and Layman Foundation provided funding. The US Fish and Wildlife Service provided housing as well as technical support. C. Kocer was supported on an assistantship from the School of Natural Resources, UNL. This is Journal Series No. 14780 from the University of Nebraska Agricultural Research Division, Lincoln, Nebraska 68583.

\section{Literature Cited}

BALSER, D. S. AND C. KINSEY. 1962. A variable size anesthetizing chamber for animal handling. J. Mass., 43:552.

BELANT, J. L. 1995. Isoflurane as an inhalation anesthetic for muskrats (Ondatra zibethicus). J. Wild. Dis., 31:573-575.

BRECK, S. W. AND J. S. GAYNOR. 2003. Comparison of isoflurane and sevoflurane for anesthesia in beaver. J. Wild. Dis., 39:387-392.

Feldman, D. B. AND J. L. SelF. 1971. Sedation and anesthesia of the Virginia opossum, Didelphis virginiana. Lab. Anim. Sci., 21:717-720.

Gaynor, J. S., J. Wimsatt, C. Mallinckrodt and D. Biggins. 1997. A comparison of sevoflurane and isoflurane for short-term anesthesia in polecats (Mustela eversmanni). J. Zoo Wild. Med., 28:274-279.

Heath, R. B., C. Calkins, D. McAllister, W. Taylor and T. Spraker. 1996. Telazol and isoflurane field anesthesia in free-ranging Steller's sea lions (Eumetopias jubatus). J. Zoo Wild. Med., 27:35-43.

, R. Delong, V. Jameson, D. Bradley and T. Spraker. 1997. Isoflurane anesthesia in free ranging sea lion pups. J. Wild. Dis., 33:206-210.

KOCER, C. J. 2004. Mesopredator movement, abundance, and habitat selection in the Rainwater Basins of Nebraska. M.S. thesis, University of Nebraska-Lincoln, Lincoln, Nebraska, USA.

KREEGER, T. J. 2007. Handbook of Wildlife Chemical Immobilization. International Wildlife Veterinary Services, Laramie, Wyoming.

A. Vargas, G. E. Plumb and E. T. Thorne. 1998. Ketamine-medetomidine or isoflurane immobilization of black-footed ferrets. J. Wild. Man., 62:654-662.

LARIVIERE, S. AND F. MESSIER. 1996a. Field anesthesia of striped skunks, Mephitis mephitis, using halothane. Can. Field Nat., 110:703-705.

AND $1996 \mathrm{~b}$. Immobilization of striped skunks with telazol. Wild. Soc. Bull., 24:713-716.

LeRCHE, P., W. M. Muir III AND R. M. BEDNARSKI. 2000. Nonrebreathing anesthetic systems in small animal practice. J. Am. Vet. Med. Assoc., 217:493-497.

LEWIS, J. C. M. 2004. Field use of isoflurane and air anesthetic equipment in wildlife. J. Zoo Wild. Med., 35:303-311. 
Mathews, F., P. Honess and S. Wolfensohn. 2002. Use of inhalation anaesthesia for wild mammals in the field. Vet. Rec., 150:785-787.

Osofsky, S. A. AND K. J. Hirsch. 2000. Chemical restraint of endangered mammals for conservation purposes: a practical primer. Oryx, 34:27-33.

SeAL, U. S. and T. J. KReEger. 1987. Chemical immobilization of furbearers, p. 191-215. In: Novak, M., Baker, J. A., Obbard, M. E. and Malloch, B. (eds.). Wild furbearer management and conservation in North America. Ontario Trappers Association, Ontario, Canada.

Taulman, J. F. AND J. H. Williamson. 1993. A simple apparatus and technique for anesthetizing raccoons. Am. Mid. Nat., 129:210-214.

CHRISTINA J. KOCER ${ }^{1}$ AND LARKIN A. POWELL ${ }^{2}$, 419 Hardin Hall, School of Natural Resources, University of Nebraska-Lincoln, Lincoln, 68583. Submitted 10 October 2007; accepted 23 June 2008.

\footnotetext{
${ }^{1}$ Present address: CT DEP Wildlife Division, Sessions Woods W.M.A., PO Box 1550, Burlington, Connecticut 06013.

${ }^{2}$ Corresponding author: email: lpowell3@unl.edu; Telephone: 402-472-6825; FAX: 402-472-2946
} 